\title{
Laparoscopic sleeve gastrectomy: Technique and results
}

\author{
Halil Coşkun, Erkan Yardımcı \\ Department of General Surgery, Bezmialem Vakif University Faculty of Medicine, Istanbul, Turkey
}

\begin{abstract}
Laparoscopic sleeve gastrectomy (LSG) has gained popularity as stand-alone procedure. The objective of this study was to describe the surgical technique and evaluate the outcomes of LSG published in the literature. Twenty-six studies with 1 to 5 years of follow-up after LSG were analyzed. Of the 26 studies, 22 reported patient gender $(n=2765)$ and $69.1 \%$ of the patients were women. Mean age of the patients was 41.05 years (22 studies; $n=2483$ patients). Mean preoperative body mass index in all twenty-four studies was 48.2 $\mathrm{kg} / \mathrm{m}^{2}$ (range: $37.2-65.3 \mathrm{~kg} / \mathrm{m}^{2}$ ). Overall mean percentage of excess weight loss after LSG reported in 17 studies was $57.7 \%$. Postoperative complication rate ranged from $0 \%$ to $15.3 \%$. Leak rate ranged from $0.7 \%$ to $5.1 \%$, and mortality rate ranged from $0 \%$ to $1.4 \%$. Eleven studies reported remission rate of postoperative co-morbidity data with follow-up period of 12 to 60 months. Existing data have identified that LSG is comparable to other accepted bariatric procedures, but long-term data is limited.
\end{abstract}

Keywords: Laparoscopic sleeve gastrectomy; obesity; outcomes; technique.

\section{Introduction}

The incidence of obesity and related comorbidities are the most significant problems in developed and developing countries. ${ }^{[1]}$ Bariatric surgery is an option for severely obese people who cannot lose weight with diet and exercise. There are different types of operative techniques for the surgical treatment of obesity including adjustable gastric band (AGB), Roux-en-Y gastric bypass (RYGB), mini-gastric bypass (MGB), biliopancreatic diversion with a duodenal switch (BPD-DS), and laparoscopic sleeve gastrectomy (LSG). ${ }^{[2]}$

LSG is an effective treatment for morbid obesity introduced as a first step in weight loss interventions in high- risk patients by Gagner et al. in 2000. ${ }^{[3]}$ Initially, LSG was performed as a part of BPD-DS. ${ }^{[4]}$ However, LSG has been regarded a primary procedure in bariatric surgery due to its several advantages such as excellent weight loss outcomes, relative technical ease, short operating time, and low rate of complications. ${ }^{[5-7]}$

LSG is a longitudinal gastrectomy including the resection of the whole fundus, greater curvature and partial antrum. As a restrictive technique, it protects gastrointestinal tract continuity and does not cause malabsorption. ${ }^{[3]}$ LSG limits food intake and causes a reduction in the levels of the ghrelin hormone leading to weight loss. 


\section{Surgical Technique}

The operation is performed in reverse Trendelenburg and French position in which the surgeon is positioned between the legs of the patient. Elastic stockings and intermittent pneumatic compressing device are applied. Generally, five-trocar approach is used for optimal visibility (Figure 1). First trocar with a diameter of $10 \mathrm{~mm}$ or $12 \mathrm{~mm}$ is placed to the upper abdomen, $1-2 \mathrm{~cm}$ above the umbilicus by Visiport TM Plus optical trocar (Covidien, Mansfield, MA, USA). The upper pressure limit for $\mathrm{CO}_{2}$ pneumoperitoneum is set as $15 \mathrm{mmHg}$. Later, this trocar is used for the camera. A $5 \mathrm{~mm}$ trocar is positioned at the subxiphoid area for the insertion of the Nathanson liver retractor (Cook Medical Inc., Bloomington, IN) to lift the left lobe of the liver and obtain optimal view of the stomach. $12 \mathrm{~mm}$ or $15 \mathrm{~mm}$ trocars are placed in the left and right upper quadrants as working channels. One $5 \mathrm{~mm}$ trocar is placed to the left subcostal anterior axillary line to retract the omental tissues and the resected part of the stomach to ease the placement of the linear reticulating stapler.

Initially, the stomach is decompressed with a nasogastric tube by the anesthesiologist. Using a Harmonic scalpel (UltraCision, Ethicon Endo-Surgery) or any other energybased device, the omentum is released from the greater curvature, starting at the opposite of the incisura angularis since it is easier to enter the lesser sac at this area. The gastroepiploic vessels and the short gastric vessels are divided using the LigaSure device (Covidien, Mansfield, MA, USA).

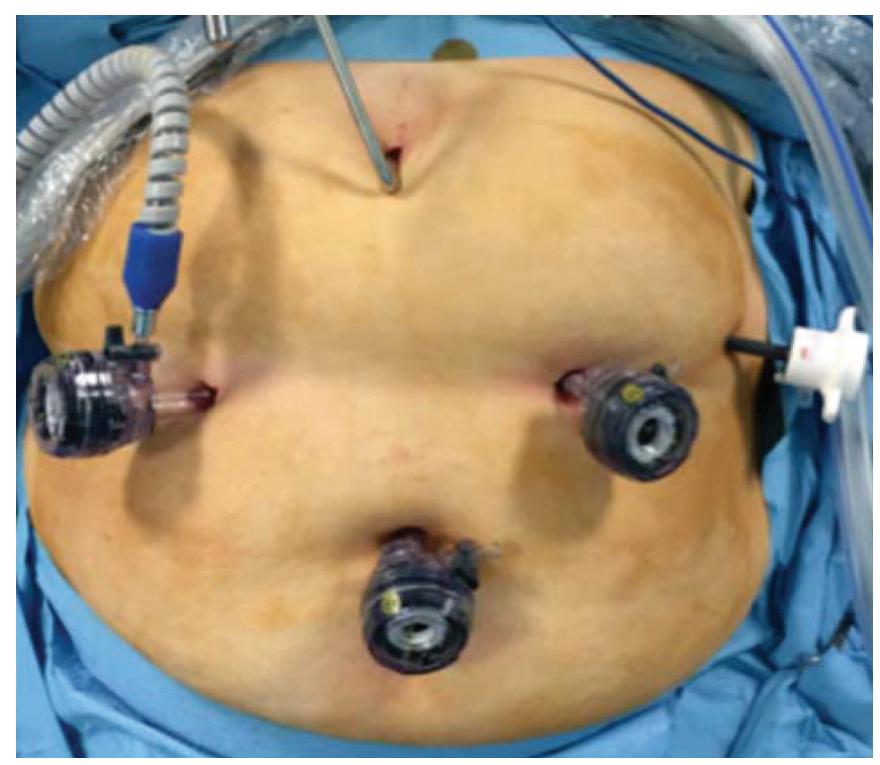

Figure 1. Localization of the trocars and the liver retractor for LSG.
Next, the greater curvature is dissected up to $1 \mathrm{~cm}$ lateral to the angle of His and $2-4 \mathrm{~cm}$ proximal to the pylorus. After finishing the dissection of the greater curvature, the left crus should be exposed for the presence of hiatal hernia. If a hiatal hernia is identified, it should be repaired. Complete mobilization of the fundus including removal of the fat pad located at the gastroesophageal junction before the transection is regarded as the critical point for the success of the technique. While holding up the stomach with $5 \mathrm{~mm}$ grasper, the surgeon carefully dissects the gastro-pancreatic area preserving the left gastric artery and its branches.

A calibrating bougie (not less than 32F) is inserted by the anesthesiologist into the stomach and passed through the pylorus after the stomach had been fully mobilized. The stomach is divided using linear reticulating stapler with a $60 \mathrm{~mm}$ cartridge (Echelon, Ethicon Endo-Surgery) inserted into the abdomen via the right sided 10 to $12 \mathrm{~mm}$ trocar. In order to create a straight staple line, a good lateral traction of the stomach should be performed via the grasper inserted at the left upper quadrant trocar. First stapler is fired at a point $2-4 \mathrm{~cm}$ proximal to the pylorus, followed by the remaining staplers fired in cranial direction along the greater curvature of the stomach (Figure 2). The closed height of the stapler should be higher than 2 $\mathrm{mm}$ due to fact that the thickest part of the stomach is in the antrum. Therefore, green or black cartridges are used for the first two firings. Blue or purple cartridges (closed height should be $1.5-2.25 \mathrm{~mm}$ ) are used for the resection of the upper stomach. Approximately, 5-7 cartridges are necessary for completing the transection (Figure 3).

Any staple line bleeding is strengthened with clips. The calibrating bougie is removed and changed to a nasogastric tube. Methylene blue is injected from the tube to test for leakage. Staple line reinforcement is performed using Tisseel. The resected stomach is removed via 12 or $15 \mathrm{~mm}$ left quadrant trocar and a closed-suction drain is placed near the staple line. The fascia of the openings is not closed. The incisions are sutured after removing the liver retractor and the trocars.

\section{Results}

\section{Patient Characteristics}

Of the twenty-six studies, twenty-two reported patient gender $(n=2765)$ and $69.1 \%$ of the patients were women. Mean age of the patients was 41.05 ( 22 studies, $n=2483$ patients). 


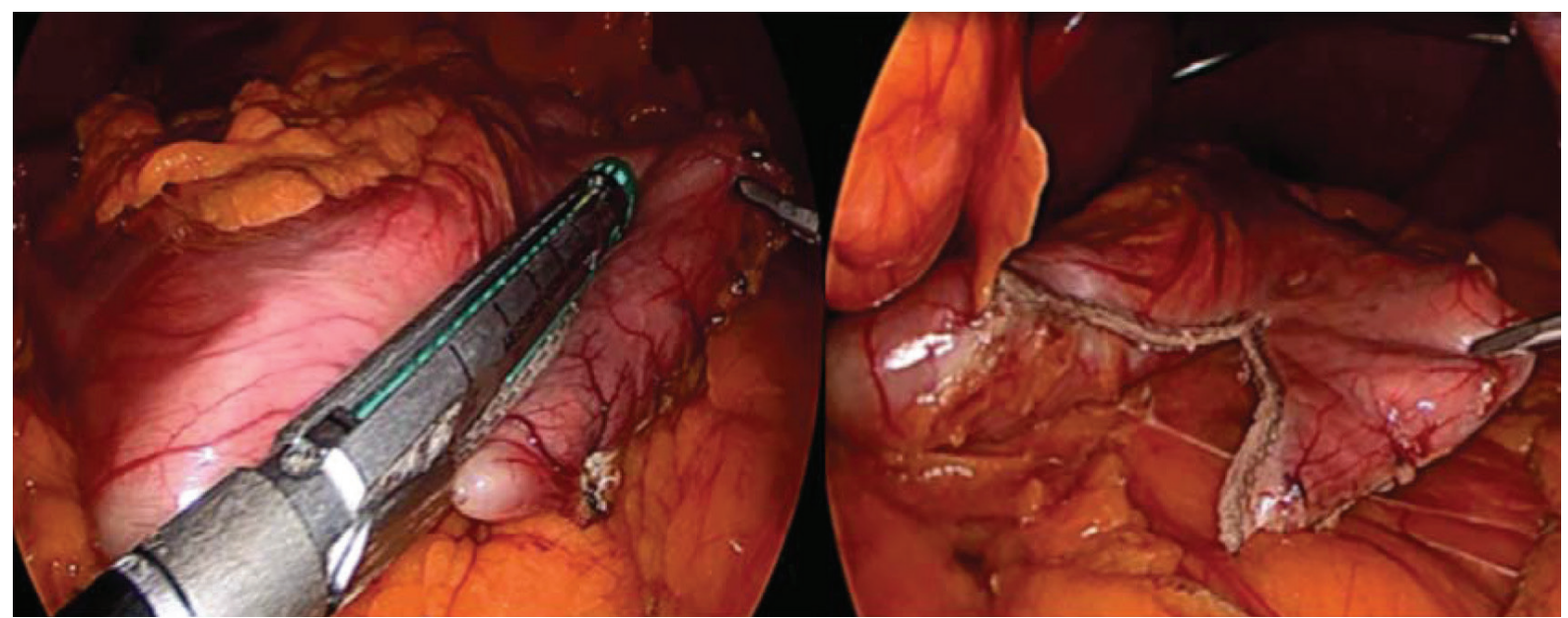

Figure 2. Creation of the gastric tube.

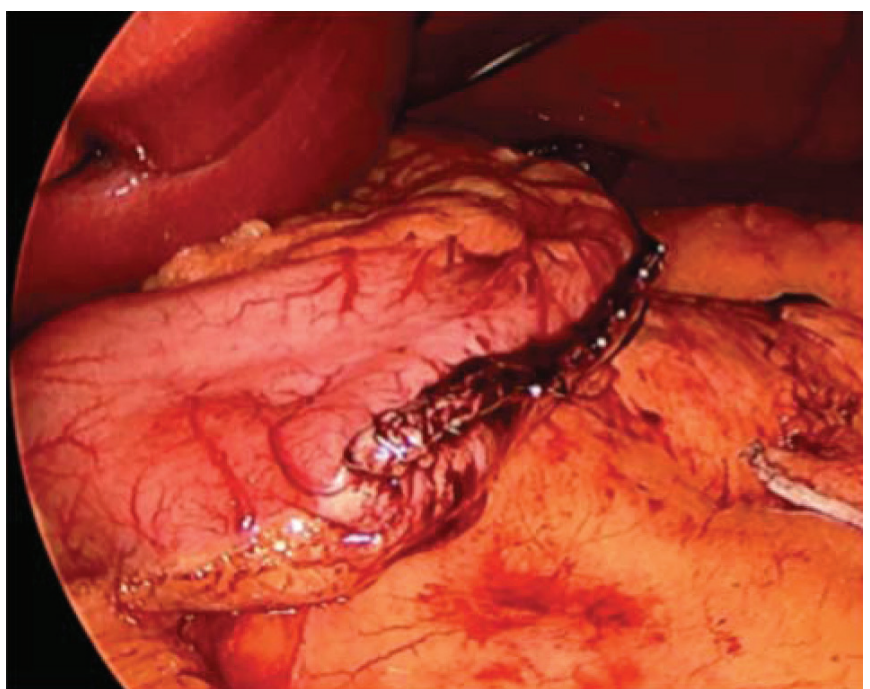

Figure 3. The gastric tube after resection.

Mean preoperative body mass index (BMI) in all twenty-four studies was $48.2 \mathrm{~kg} / \mathrm{m}^{2}$ (range $=37.2$ to $65.3 \mathrm{~kg} / \mathrm{m}^{2}$ ).

\section{Weight Loss}

Overall mean percentage of excess weight loss (\%EWL) after LSG was reported $57.7 \%$ in seventeen studies (range $=46$ to $86 \%$ ) (Table 1). The follow-up period for the weight loss data was 11-60 months. The long-term ( $\geq 60$ months after surgery) mean \% EWL was $64.8 \%$ in six studies.

\section{Effect on Co-Morbidities}

Eleven studies ( $\mathrm{n}=1539)$ included improvement or remission rate of the postoperative co-morbidity data with a follow-up period of 12-60 months (Table 2). Significant improvements were seen in comorbidities including type II diabetes mellitus (T2DM), arterial hypertension, hyperlipidemia, and sleep apnea.

\section{Complications and Operative Mortality}

The postoperative complication rate ranged from $0 \%$ to $15.3 \%$ (Table 3). The leak rate ranged from $0.7 \%$ to $5.1 \%$ in sixteen studies ( $\mathrm{n}=1981$ patients). The rate of 30 day postoperative mortality was reported as from $0 \%$ to $1.4 \%$ in twenty-three studies. ${ }^{[12,19,23,27]}$

\section{Discussion}

LSG has been performed increasingly as a new and primary bariatric procedure worldwide. In the past, LSG was performed as a planned staged procedure before RYGB or BPD/DS. Initial reports showed that LSG reduced surgical risks and co-morbidities as a staged approach in super obese and high-risk patients. Durable weight loss and co-morbid condition remission were seen in the longterm follow-up after LSG. Most studies showed that rates of the complications such as leak, bleeding, stricture, and mortality were less after LSG compared with other bariatric procedures.

In the study published by Cottam et al., one hundred and twenty-six patients (53\% female), regarded high-risk with a mean BMI of $65.3 \mathrm{~kg} / \mathrm{m}^{2}$, underwent LSG as a first stage approach. American Society of Anesthesiologists physical status score (ASA) was III or IV in most patients (94\%) and the mean number of co-morbidities per patient was 9.3 (range: 3 to 17). ${ }^{[7]}$ After one-year follow-up period, the mean \%EWL was $46 \%$ and the average number of comorbid conditions per patient had decreased to six. In this study, the complication rate was $14 \%$ including stricture, leak, pulmonary embolism, respiratory distress (requiring $>24 \mathrm{~h}$ ventilator support), and renal insufficiency not requiring dialysis. Only thirty-six patients underwent 
Table 1. Weight loss outcomes after LSG

\begin{tabular}{|c|c|c|c|c|c|}
\hline Reference & Year & Patients (n) & Preoperative BMI $\left(\mathrm{kg} / \mathrm{m}^{2}\right)$ & Follow-up (mo) & $\% E W L$ \\
\hline Cottam et al. ${ }^{[24]}$ & 2006 & 126 & 65.3 & 12 & 46 \\
\hline Hamoui et al. ${ }^{[5]}$ & 2006 & 118 & 55 & 24 & 47.3 \\
\hline Lee et al. ${ }^{[21]}$ & 2007 & 216 & 49 & 24 & 59 \\
\hline Nocca et al. ${ }^{[20]}$ & 2007 & 163 & 45.9 & 24 & 61.5 \\
\hline Weiner et al. ${ }^{[13]}$ & 2007 & 120 & 60.7 & 60 & NR \\
\hline Yang $O$ et al..$^{[8]}$ & 2008 & 138 & 50.6 & 24 & 46 \\
\hline Parikh et al. ${ }^{[12]}$ & 2008 & 135 & 60.1 & 12 & 47.3 \\
\hline Felberbauer et al. ${ }^{[18]}$ & 2008 & 126 & 48.1 & 19 & NR \\
\hline Rubin et al. ${ }^{[15]}$ & 2008 & 120 & 43.5 & 11 & NR \\
\hline Fuks et al. ${ }^{[24]}$ & 2009 & 135 & 48.8 & 12 & 49.4 \\
\hline Stroh et al. ${ }^{[25]}$ & 2009 & 144 & 54.5 & 24 & NR \\
\hline Bobowicz et al. ${ }^{[26]}$ & 2011 & 112 & 44.6 & 22 & 46.6 \\
\hline Chopra et al. ${ }^{[9]}$ & 2011 & 174 & 48.9 & 36 & 58.9 \\
\hline Rawlins et al. ${ }^{[27]}$ & 2012 & 49 & 65 & 60 & 86 \\
\hline Catheline et al. ${ }^{[28]}$ & 2013 & 45 & 49.1 & 60 & 50.7 \\
\hline Sieber et al. ${ }^{[29]}$ & 2013 & 54 & 43 & 60 & 57.4 \\
\hline Zachariah et al. ${ }^{[10]}$ & 2013 & 228 & 37.4 & 60 & 63.7 \\
\hline Bellows et al. ${ }^{[30]}$ & 2014 & 63 & 51.8 & 17 & 47.2 \\
\hline Boza et al. ${ }^{[22]}$ & 2014 & 161 & 34.9 & 60 & 62.9 \\
\hline
\end{tabular}

Table 2. Co-morbidity remission and improvement rate after LSG

\begin{tabular}{|c|c|c|c|c|c|c|c|}
\hline Reference & Year & $\begin{array}{l}\text { Patients } \\
\text { (n) }\end{array}$ & $\begin{array}{l}\text { Follow-up } \\
\text { (mo) }\end{array}$ & T2DM $^{*}$ & $\mathrm{HTN}^{*}$ & Hyperlipidemia ${ }^{*}$ & Sleep apnea* \\
\hline Hamoui et al. ${ }^{[5]}$ & 2006 & 118 & 24 & $47 / 22$ & $15 / 116$ & NR & NR \\
\hline Cottam et al. ${ }^{[31]}$ & 2006 & 126 & 12 & $81 / 11$ & $78 / 7$ & $73 / 5$ & $80 / 7$ \\
\hline Moon Han et al. ${ }^{[32]}$ & 2005 & 60 & 12 & $100 / 0$ & $93 / 7$ & $45 / 30$ & 100/NR \\
\hline Weiner et al..$^{[11]}$ & 2007 & 120 & 60 & $14 / 86$ & $42 / 55$ & $5 / 77$ & $39 / 61$ \\
\hline Yang $O$ et al. ${ }^{[8]}$ & 2008 & 138 & 24 & $39 / 49$ & $29 / 48$ & $48 / 39$ & $52 / 33$ \\
\hline Bobowicz et al. ${ }^{[26]}$ & 2011 & 112 & 22 & $41 / 27$ & $33 / 28$ & NR & $0 / 100$ \\
\hline Chopra et al. ${ }^{[9]}$ & 2011 & 174 & 36 & $33 / 51$ & $26 / 23$ & NR & $23 / 67$ \\
\hline Basso et al. ${ }^{[11]}$ & 2011 & 200 & 12 & $88 / 12$ & $57 / 31$ & NR & $56 / 33$ \\
\hline Zachariah et al. ${ }^{[10]}$ & 2013 & 228 & 60 & $66 / N R$ & $100 / \mathrm{NR}$ & $50 / N R$ & NR \\
\hline Zhang et al. ${ }^{[33]}$ & 2013 & 200 & 12 & $58 / \mathrm{NR}$ & $38 / \mathrm{NR}$ & $63 / N R$ & $91 / \mathrm{NR}$ \\
\hline Bellows et al. ${ }^{[30]}$ & 2014 & 63 & 17 & $50 / 20$ & $48 / 33$ & 96/NR & NR \\
\hline
\end{tabular}

T2DM: Type 2 diabetes mellitus, HTN: Arterial hypertension. *Remission/Improvement rate (\%).

second-stage LRYGB after a mean interval of 12 months (range: 4-22 months). The mean \%EWL was 33\% in this subgroup after 6 months follow-up period.

Another study by Parikh et al. included one hundred and thirty-five high-risk patients with a mean BMI of $60.1 \mathrm{~kg} /$ $\mathrm{m}^{2} .{ }^{[13]}$ The greater number of these patients $(79 \%)$ under- went LSG as a planned staged procedure before RYGB or BPD-DS within 11 months. In their series, after a follow-up period of 12 months, the mean \%EWL and BMI was 47.3\% and $44.3 \mathrm{~kg} / \mathrm{m}^{2}$, respectively. This study demonstrated that weight loss was not related to the bougie size at midterm follow-up. However, some studies showed that larger bougies cause weight regain. Therefore, it is thought that 
Table 3. Surgical outcomes after LSG

\begin{tabular}{|c|c|c|c|c|c|c|c|c|c|}
\hline Reference & Year & Patient & $\begin{array}{l}\text { Follow-up } \\
\text { (mo) }\end{array}$ & $\begin{array}{l}\text { Leak } \\
(\%)\end{array}$ & $\begin{array}{l}\text { Bleeding } \\
\text { (\%) }\end{array}$ & $\begin{array}{l}\text { Stricture } \\
(\%)\end{array}$ & $\begin{array}{c}\text { Readmission } \\
\text { (\%) }\end{array}$ & $\begin{array}{c}\text { Complications } \\
\text { (\%) }\end{array}$ & $\begin{array}{c}\text { Mortality } \\
\text { (\%) }\end{array}$ \\
\hline Himpens et al. ${ }^{[34]}$ & 2006 & 40 & 36 & 0 & 2.5 & 0 & 5 & NR & 0 \\
\hline Yang $O$ et al. ${ }^{[8]}$ & 2008 & 138 & 24 & 1.5 & 2.2 & 0.7 & NR & 5.07 & 0 \\
\hline Chopra et al. ${ }^{[9]}$ & 2011 & 174 & 36 & 2.1 & 2.1 & 2.1 & NR & 14 & 0 \\
\hline Basso et al. ${ }^{[1]]}$ & 2011 & 200 & 12 & 2.5 & 2.5 & NR & NR & 6 & 0.6 \\
\hline Albanopoulos et al. ${ }^{[35]}$ & 2012 & 90 & NR & 4.2 & 2 & 0 & 1 & 6.2 & 0 \\
\hline Helmiö et al. ${ }^{[36]}$ & 2012 & 121 & NR & 0 & 5.1 & 0 & 2.5 & 13.2 & 0 \\
\hline Gentileschi et al. ${ }^{[37]}$ & 2012 & 120 & NR & 1.7 & 1.7 & 0 & 0.8 & 3.3 & 0 \\
\hline Catheline et al. ${ }^{[28]}$ & 2013 & 45 & 60 & 3.8 & 1.9 & 0 & NR & 5.7 & 0 \\
\hline Zachariah et al..$^{[10]}$ & 2013 & 228 & 60 & 1.3 & 0 & 1.3 & 3.07 & 4.3 & 0.43 \\
\hline Bellows et al. ${ }^{[30]}$ & 2014 & 63 & 17 & 0 & 0 & 0 & 5 & 11 & 0 \\
\hline Boza et al. ${ }^{[22]}$ & 2014 & 161 & 60 & 0.6 & 0 & 0.6 & NR & 3.7 & 0 \\
\hline
\end{tabular}

the size of bougies is one of the important factors contributing to durable weight loss. ${ }^{[11,34]}$

The other important point to the weight loss outcome after LSG might be the changes in the plasma levels of ghrelin. Ghrelin-producing cells are mainly located in the gastric fundus and this part of the stomach is completely resected in LSG, and some studies showed that the plasma ghrelin levels decreases after LSG. ${ }^{[34,35]}$

LSG results have been reported a primary procedure since 2006. ${ }^{[36]}$ Felberbauer et al. reported one hundred and twenty-six patients who underwent LSG as a primary bariatric operation. ${ }^{[14]}$ Mean preoperative BMI and excessive weight of the patients were $48 \mathrm{~kg} / \mathrm{m}^{2}$ and $70.4 \mathrm{~kg}$, respectively. After a mean follow-up of 19.1 months, patients had lost between $6.7 \%$ and $130 \%$ of their excessive weight.

The complication rate was found $3.17 \%$ and no mortality was seen.

Some studies reported that LSG might be a revisional procedure for insufficient weight loss after LAGB. ${ }^{[1,38]}$ A prospective multicenter study reported by Noccademonstrated that $13.4 \%$ of the one hundred and sixty-three patients were performed LSG after failed LAGB. ${ }^{[37]}$

In the study of Lee et al. in 2007, LSG was compared to LAGB, LRGB and duodenal switch (DS). Of these eight hundred and forty-six patients, 271 (32\%) had LAGB, 216 (25\%) LSG, 303 (36\%) LRGB, and 56 (7\%) DS. ${ }^{[9]}$ LSG patients had higher mean BMI level $\left(49 \mathrm{~kg} / \mathrm{m}^{2}\right)$ than LRGB $\left(46 \mathrm{~kg} / \mathrm{m}^{2}\right)$ and DS $\left(47 \mathrm{~kg} / \mathrm{m}^{2}\right)$ patients. However, LAGB patients were less obese (mean BMI $42 \mathrm{~kg} / \mathrm{m}^{2}$ ) than the other patients. Percentage of EWL was greater in the LRGB and DS patients (75\% and 79\%, respectively) and the least in the LAGB patients (47\%). Mean \%EWL in LSG group was $59 \%$ in one year. The complication rate was lower in the LSG group (16\%) and there was no mortality in any groups.

Some studies have demonstrated that an important benefit of LSG is durable weight loss within five years after surgery. ${ }^{[23,25,34]}$ The mean \%EWL ranged from $43 \%$ at 84 months after surgery in the study by Eid et al. to $69 \%$ at $>96$ months after surgery in the study from Sarela et al., but two studies had very small number of patients. ${ }^{[13,38,39]}$ Boza et al. reported long-term outcomes after LSG when performed as a primary bariatric procedure. ${ }^{[25]}$ They described surgical success as EWL $\%>50 \%$ and remission of co-morbidities without any medication at fifth year. In

this study, mean preoperative BMI of one hundred and sixty-one patients was $34.9 \mathrm{~kg} / \mathrm{m}^{2}, 70 \%$ of the patients completed 5 years follow-up period and the mean of BMI at the postoperative fifth year was $28.5 \mathrm{~kg} / \mathrm{m}^{2}$. Postoperative complications included surgical wound infection, portomesenteric thrombosis, haemoperitoneum, stapleline leak and antral stenosis which was seen six patients (3.7\%). Only four patients (2.5\%) required a reoperation due to antral stenosis and weight regain in one and three patients, respectively, at 5 years follow-up.

Most of the studies showed that co-morbid conditions like arterial hypertension, T2DM, dyslipidemia, sleep apnea and insulin resistance reduced after LSG. ${ }^{[1,12,27]}$ In these series, it was shown that T2DM remission rate was between 33 to $100 \%$ in mid-term follow-up. ${ }^{[19,27]}$ Zachariah et al. published long-term follow-up (60 months) outcomes including T2DM and arterial hypertension resolution rate, which were found $66 \%$ and $100 \%$, respectively. ${ }^{[23]}$ In an- 
other study published by Boza et al., T2DM and arterial hypertension remission rate were found to be lower than that of the others (57\% and $40 \%$, respectively). ${ }^{[25]}$ In a prospective review published by Yang et al., $48 \%$ of the patients had resolution in dyslipidemia and $52 \%$ of the patients were cured from obstructive sleep apnea (OSAS). ${ }^{[12]}$ A prospective study by Basso et al. compared results of LSG (200 patients) and BPD-DS (100 patients). ${ }^{[25]}$ OSAS was present in $19 \%$ and $29 \%$ of the patients in LSG and BPD-DS groups, respectively. In this study, resolution rate of OSAS was identified in each group after one-year follow-up (56\% and 50\%, respectively).

\section{Conclusion}

The results of recent studies demonstrate that LSG is an effective weight loss procedure with an excellent co-morbid reduction rate. Therefore, it can be performed with a low complication rate as a primary procedure. The existing data have identified that LSG is comparable to the other accepted bariatric procedures but long-term data is limited.

\section{References}

1. Andreas A, Adamantios M, Antonios A, Theofilos R, Christos T, Theodoros D. Laparoscopic Sleeve Gastrectomy for Morbid Obesity with Intra-operative Endoscopy: Lessons We Learned After 100 Consecutive Patients. Obes Surg 2015;25:1223-8.

2. Glatt $D$, Sorenson T. Metabolic and bariatric surgery for obesity: a review. S D Med 2011;Spec No:57-62.

3. D'Hondt M, Vanneste S, Pottel H, Devriendt D, Van Rooy F, Vansteenkiste F. Laparoscopic sleeve gastrectomy as a single-stage procedure for the treatment of morbid obesity and the resulting quality of life, resolution of comorbidities, food tolerance, and 6-year weight loss. Surg Endosc 2011;25:2498-504.

4. Ren CJ, Patterson E, Gagner M. Early results of laparoscopic biliopancreatic diversion with duodenal switch: a case series of 40 consecutive patients. Obes Surg 2000;10:514-23.

5. Hamoui N, Anthone GJ, Kaufman HS, Crookes PF. Sleeve gastrectomy in the high-risk patient. Obes Surg 2006;161445-9.

6. Helmiö M, Victorzon M, Ovaska J, Leivonen M, Juuti A, Peromaa-Haavisto $\mathrm{P}$, et al. Comparison of short-term outcome of laparoscopic sleeve gastrectomy and gastric bypass in the treatment of morbid obesity: A prospective randomized controlled multicenter SLEEVEPASS study with 6-month follow-up. Scand J Surg 2014;103:175-81.

7. Ozmen MM, Gagner M. Laparoscopic sleeve gastrectomy: techniques and pitfalls to avoid complications. Eur $\mathrm{J}$ Endosc Laparosc Surg 2014;1:55-8.

8. Ou Yang O, Loi K, Liew V, Talbot M, Jorgensen J. Staged laparoscopic sleeve gastrectomy followed by Roux-en-Y gastric bypass for morbidly obese patients: a risk reduction strategy. Obes Surg 2008;18:1575-80.

9. Chopra A, Chao E, Etkin Y, Merklinger L, Lieb J, Delany H. Laparoscopic sleeve gastrectomy for obesity: can it be considered a definitive procedure? Surg Endosc 2012;26:831-7.

10. Zachariah SK, Chang PC, Ooi AS, Hsin MC, Kin Wat JY, Huang CK. Laparoscopic sleeve gastrectomy for morbid obesity: 5 years experience from an Asian center of excellence. Obes Surg 2013;23:939-46.

11. Basso N, Casella G, Rizzello M, Abbatini F, Soricelli E, Alessandri $\mathrm{G}$, et al. Laparoscopic sleeve gastrectomy as first stage or definitive intent in 300 consecutive cases. Surg Endosc 2011;25:444-9.

12. Parikh M, Gagner $M$, Heacock $L$, Strain G, Dakin G, Pomp A. Laparoscopic sleeve gastrectomy: does bougie size affect mean \%EWL? Short-term outcomes. Surg Obes Relat Dis 2008;4:528-33.

13. Weiner RA, Weiner S, Pomhoff I, Jacobi C, Makarewicz W, Weigand G. Laparoscopic sleeve gastrectomy-influence of sleeve size and resected gastric volume. Obes Surg 2007;17:1297-305.

14. Bohdjalian A, Langer FB, Shakeri-Leidenmühler $S$, Gfrerer $L$, Ludvik B, Zacherl J, et al. Sleeve gastrectomy as sole and definitive bariatric procedure: 5 -year results for weight loss and ghrelin. Obes Surg 2010;20:535-40.

15. Rubin M, Yehoshua RT, Stein M, Lederfein D, Fichman S, Bernstine $H$, et al. Laparoscopic sleeve gastrectomy with minimal morbidity. Early results in 120 morbidly obese patients. Obes Surg 2008;18:1567-70.

16. Karamanakos SN, Vagenas K, Kalfarentzos F, Alexandrides TK. Weight loss, appetite suppression, and changes in fasting and postprandial ghrelin and peptide-YY levels after Roux-en-Y gastric bypass and sleeve gastrectomy: a prospective, double blind study. Ann Surg 2008;247:401-7.

17. Brethauer SA, Hammel JP, Schauer PR. Systematic review of sleeve gastrectomy as staging and primary bariatric procedure. Surg Obes Relat Dis 2009;5:469-75.

18. Felberbauer FX, Langer F, Shakeri-Manesch S, Schmaldienst E, Kees M, Kriwanek S, et al. Laparoscopic sleeve gastrectomy as an isolated bariatric procedure: intermediate-term results from a large series in three Austrian centers. Obes Surg 2008;18:814-8.

19. Eid GM, Brethauer S, Mattar SG, Titchner RL, Gourash W, Schauer PR. Laparoscopic sleeve gastrectomy for super obese patients: forty-eight percent excess weight loss after 6 to 8 years with 93\% follow-up. Ann Surg 2012;256:262-5.

20. Nocca D, Krawczykowsky D, Bomans B, Noël P, Picot MC, Blanc PM, et al. A prospective multicenter study of 163 sleeve gastrectomies: results at 1 and 2 years. Obes Surg 2008; 18:560-5.

21. Lee $\mathrm{CM}$, Cirangle $\mathrm{PT}$, Jossart GH. Vertical gastrectomy for morbid obesity in 216 patients: report of two-year results. Surg Endosc 2007;21:1810-6.

22. Boza C, Daroch D, Barros D, León F, Funke R, Crovari F. Longterm outcomes of laparoscopic sleeve gastrectomy as a pri- 
mary bariatric procedure. Surg Obes Relat Dis 2014;10:112933.

23. Sarela Al, Dexter SP, O'Kane M, Menon A, McMahon MJ. Long-term follow-up after laparoscopic sleeve gastrectomy: 8-9-year results. Surg Obes Relat Dis 2012;8:679-84.

24. Fuks D, Verhaeghe $P$, Brehant $O$, Sabbagh $C$, Dumont F, Riboulot $\mathrm{M}$, et al. Results of laparoscopic sleeve gastrectomy: a prospective study in 135 patients with morbid obesity. Surgery 2009;145:106-13.

25. Stroh C, Birk D, Flade-Kuthe R, Frenken M, Herbig B, Höhne S, et al; Bariatric Surgery Working Group. Results of sleeve gastrectomy-data from a nationwide survey on bariatric surgery in Germany. Obes Surg 2009;19:632-40.

26. Bobowicz M, Lehmann A, Orlowski M, Lech P, Michalik M. Preliminary outcomes 1 year after laparoscopic sleeve gastrectomy based on Bariatric Analysis and Reporting Outcome System (BAROS). Obes Surg 2011;21:1843-8.

27. Rawlins L, Rawlins MP, Brown CC, Schumacher DL. Sleeve gastrectomy: 5-year outcomes of a single institution. Surg Obes Relat Dis 2013;9:21-5.

28. Catheline JM, Fysekidis M, Bachner I, Bihan H, Kassem A, Dbouk R, et al. Five-year results of sleeve gastrectomy. J Visc Surg 2013;150:307-12.

29. Sieber P, Gass M, Kern B, Peters T, Slawik M, Peterli R. Fiveyear results of laparoscopic sleeve gastrectomy. Surg Obes Relat Dis 2014;10:243-9.

30. Bellows CF, Gauthier JM, Webber LS. Bariatric aftercare and outcomes in the Medicaid population following sleeve gastrectomy. JSLS 2014;18. pii: e2014.00280.
31. Cottam D, Qureshi FG, Mattar SG, Sharma S, Holover S, Bonanomi G, et al. Laparoscopic sleeve gastrectomy as an initial weight-loss procedure for high-risk patients with morbid obesity. Surg Endosc 2006;20:859-63.

32. Moon Han S, Kim WW, Oh JH. Results of laparoscopic sleeve gastrectomy (LSG) at 1 year in morbidly obese Korean patients. Obes Surg 2005; 15:1469-75.

33. Zhang N, Maffei A, Cerabona T, Pahuja A, Omana J, Kaul A. Reduction in obesity-related comorbidities: is gastric bypass better than sleeve gastrectomy? Surg Endosc 2013;27:127380.

34. Himpens J, Dapri G, Cadière GB. A prospective randomized study between laparoscopic gastric banding and laparoscopic isolated sleeve gastrectomy: results after 1 and 3 years. Obes Surg 2006;16:1450-6.

35. Albanopoulos K, Alevizos L, Flessas J, Menenakos E, Stamou $\mathrm{KM}$, Papailiou J, et al. Reinforcing the staple line during laparoscopic sleeve gastrectomy: prospective randomized clinical study comparing two different techniques. Preliminary results. Obes Surg 2012;22:42-6.

36. Helmiö M, Victorzon M, Ovaska J, Leivonen M, Juuti A, Jaser $\mathrm{N}$, et al. SLEEVEPASS: a randomized prospective multicenter study comparing laparoscopic sleeve gastrectomy and gastric bypass in the treatment of morbid obesity: preliminary results. Surg Endosc 2012;26:2521-6.

37. Gentileschi P, Camperchioli I, D'Ugo S, Benavoli D, Gaspari AL. Staple-line reinforcement during laparoscopic sleeve gastrectomy using three different techniques: a randomized trial. Surg Endosc 2012;26:2623-9. 